\title{
Indigenous Principles Decolonizing Teacher Education: What We Have Learned
}

\author{
Kathy Sanford, Lorna Williams, Tim Hopper, and Catherine McGregor \\ University of Victoria
}

\begin{abstract}
Although teacher education programs across the country are currently under significant review and reform, little attention is paid to the importance of Indigenous principles that could inform or transform them. Attention to Indigenous principles such as those presented in this paper can, we believe, serve to decolonize teacher education, offering programs that enable greater success for a wider array of diverse students, both Aboriginal and non-Aboriginal, and address their needs and interests. The intent of this paper is to draw attention to the ways Indigenous principles offered by Lil'wat scholar Lorna Williams have influenced one teacher education program, and to share some of the ways that these principles have been enacted within the program. We offer our perspectives as narrative accounts of what we have done in our courses and in our teacher education program that reflect the principles explained in the paper. We do not feel we can express this perspective any different other than to recount shifts made and our observations as educators. These could be expressed as case studies but this would only be paying lip service to claiming a methodology that was not really followed. We offer this paper more as a sharing of narratives drawn to the indigenous principles. Authenticity comes from our common perceptions from different perspectives in the program.
\end{abstract}

Keywords: Indigenous Knowledge; Teacher Education; Decolonization 


\section{Indigenous Principles Decolonizing Teacher Education: What We Have Learned}

Website listing key Lil'wat learning and teaching concepts with pronunciation of associate terms in the Lil'wat dialect: https://sites.google.com/site/lulwatprinciples/home

Teacher education programs around the world are continually undergoing change; however, fundamental beliefs underpinning the programs have not significantly shifted (Phelan, 2011; Darling-Hammond, 2006). They still reflect hegemonic Euro-American-centric values influenced and shaped by neoliberal discourses of hierarchical models drawing from "expert" knowledge (Battiste, 2002) where competition, individualism, and scientific research have dominated educational thinking. Individual educators have sought to bring alternative processes into their classroom practices that reflect Indigenous principles of living and learning (Little Bear, 2009; Kanu, 2011). Although there are instances of changing conceptions of teacher education programming (e.g., Clarke, Erickson, Collins, \& Phelan, 2005; Smits et al., 2005), for the most part there has been little challenge to the European model of education that has existed for over one hundred years. Essentially, the following four areas make up initial teacher education:

- foundational knowledge in education-related aspects of philosophy of education, history of education, educational psychology, and sociology of education,

- skills in assessing student learning, supporting English Language learners, using technology to improve teaching and learning, and supporting students with special needs,

- content-area and methods for teaching a subject area with related knowledge and skills, and

- $\quad$ practice at classroom teaching through practicum experiences.

Conventionally, these areas compete for curriculum time in order to pass on expert knowledge to the novice teachers in form of course lectures, activities, and assignments. Knowledge is seen as objects of knowing to be retained, repeated back, and applied within an array of assignments that serve as evaluations of understanding. Students are rewarded with higher marks than peers for showing a better understanding and more effective representation of their learning. This model of teacher education results in a colonizing effect, with neoliberal discourses made manifest in public schooling through testing, examinations, and projects evaluated by predetermined standards, maintaining students' belief in the ideology of competing for the top marks and working as individuals striving for personal success. Students re-present colonial content as evidence for their transition into the role of teacher, focusing on their individual advancement into a career as teacher, and then teaching students to learn in the same way (Giroux, 2012).

The colonizing model of teacher education is no longer sufficient for providing the education needed by new generations of learners who will be facing a world with challenges that they will not be able to address with the current approaches to education. Increasingly, schools need teachers who are able to learn through adaptation and flexibility, engage in meaningful experiences that connect to students' social lives, collaborate and share, and use innovative approaches to develop and share materials (Trilling \& Fadel, 2009). Teachers need to be aware of and able to interrupt the repetitive neoliberal discourses that cut off students and their families through notions of individualism, power, and mistrust. In the 21st century, teachers need to 
develop strong personal and professional identities and self-confidence, and engage in programs that recognize a wide range of student backgrounds, needs, interests, and abilities based on cultural, gendered, physical, and socio-economic characteristics. Teacher education programs need to recognize the wide array of skills and knowledge that exist among their students, create program spaces to develop professional knowledge and expertise that develops their facility, and adapt to the rapidly changing demands of the professional workplace. Rather than seeking simplistic solutions to complex problems, new educators need to embrace complexity and have the skills and confidence to call on their own expertise and the expertise of others in order to work through challenging problems and situations. Working in learning communities (Wenger, 1998), these new professionals need to share their knowledge with others in order to effectively address professional responsibilities.

We (two white Canadian females, a British white male, and one female member of the Lil'wat First Nation of Mount Currie) draw on our collective experience as teacher educators across four academic units within a Faculty of Education. Attracted to a course taught by our First Nations' colleague on Learning and Teaching in an Indigenous World, we sought to embrace the Indigenous pedagogical principles such as inclusivity, community building, recognition and celebration of individual uniqueness to inform the development of our respective courses. Lorna Williams speaks the Lil'wat language, and she was part of a team that documented the language and created learning resources for use in classrooms. She identified these principles over many years of working with learners in classrooms and discussing the ideas of learning and teaching with wisdom keepers in her community. As noted in Williams and Tanaka (2007), humankind is at a historic point that demands a culturally combined approach to curriculum reform, rejecting universal truths, which flow from the colonizer to the colonized. Instead, they suggest that we need to open up a "third space" in teacher education programs where cultural discourses can weave together, offering alternative paths to knowledge and community wisdom.

In Figure 1, neoliberalism is shown as a discourse that enables the perception of reality in materialistic terms, leading to individualistic and competitive values, seeking always to be better than others, seeking dichotomous ways to be right, implying a singular "truth" that must be sought out and learned. Schooling influenced and shaped by neoliberalist discourse-valuing linear over cyclical progression, competition over collaboration, dualism over complexity, and product over process-is exclusionary and does not accommodate the learning needs of many students. It does not take into account the diversity of students in $21^{\text {st }}$ century society in relation to culture, race, gender, sexual orientation, economic potential, disability, or beliefs (Giroux, 1988, 2012; McLaren, 1988; Asante, 1999). Additionally, it does not embrace learning in all its complexity, informed by culture, experience, environment, and the more-than-human world. In this paper, we will suggest the importance of embracing alternative ways of conceptualizing education for all students. Drawing on principles of Indigenous education as highlighted in Figure 1, we believe we can shift the ways we have maintained educational experiences for prospective teachers. In so doing, we are shifting away from a Euro-American centrism increasingly being overly influenced by neoliberal discourses. 


\begin{tabular}{|c|c|}
\hline \multicolumn{2}{|r|}{ Ways of knowing } \\
\hline $\begin{array}{c}\text { Euro-American-Centrism Neoliberalism } \\
\text { (Predetermined Curriculum) }\end{array}$ & $\begin{array}{c}\text { Indigenous } \\
\text { (Learner/teacher Collaboration) }\end{array}$ \\
\hline $\begin{array}{l}\text { Prescribed learning; expected outcomes pre- } \\
\text { determined }\end{array}$ & $\rightarrow$ Learning is emergent \\
\hline Teacher to student focused & $\rightarrow$ Focus on students and teacher interaction \\
\hline $\begin{array}{l}\text { Learning happens in the classroom; } \\
\text { classroom is quiet }\end{array}$ & $\begin{array}{l}\rightarrow \text { Learning happens in many locations, inside and } \\
\text { outside the school; classroom can be noisy }\end{array}$ \\
\hline Knowledge is transmitted & $\rightarrow \begin{array}{l}\text { Students construct knowledge through gathering and } \\
\text { synthesizing information }\end{array}$ \\
\hline Students work independently & $\begin{array}{l}\rightarrow \quad \text { Students work in pairs, groups, or alone depending on } \\
\text { the purpose of the activity }\end{array}$ \\
\hline Teacher evaluates student learning & $\rightarrow \begin{array}{l}\text { Assessment is used in context to promote and } \\
\text { diagnose learning }\end{array}$ \\
\hline $\begin{array}{l}\text { Teacher monitors and corrects students' } \\
\text { responses }\end{array}$ & $\begin{array}{l}\rightarrow \quad \begin{array}{l}\text { Learners are guided to find their own solutions and } \\
\text { answer their own questions }\end{array}\end{array}$ \\
\hline $\begin{array}{l}\text { Teachers evaluate student learning; teaching } \\
\text { and assessing are separate }\end{array}$ & $\rightarrow \begin{array}{l}\text { Students evaluate their own learning; teachers also } \\
\text { evaluate; teaching and assessing are intertwined }\end{array}$ \\
\hline $\begin{array}{l}\text { Students are ranked according to pre- } \\
\text { determined criteria }\end{array}$ & $\begin{array}{l}\rightarrow \text { Students have multiple opportunities for success and } \\
\text { quiet recognition }\end{array}$ \\
\hline Teacher chooses what is to be learned & $\begin{array}{l}\rightarrow \text { Students have some choice of learning activities and } \\
\text { topics }\end{array}$ \\
\hline Focus is on a single discipline & $\begin{array}{l}\Rightarrow \text { Approach is compatible with multi and inter- } \\
\text { disciplinary investigation }\end{array}$ \\
\hline Culture is competitive and individualistic & $\rightarrow$ Culture is cooperative, collaborative, and supportive \\
\hline
\end{tabular}

Figure 1. Contrasting Euro-American-centrism influenced by neoliberal discourses and Indigenous ways of knowing.

Though not comprehensive, the intents in Indigenous teaching indicated in Figure 1 implies that understandings can provide a lens for educators to think about different ways of connecting with learners, valuing their knowledge, and helping them to move forward successfully into the world. Euro-American conventions, increasingly shaped by neoliberals whose focus on the singular truth and the right way, has stunted the growth of not only Aboriginal students, but of all students, and in this paper we will suggest that teacher education can learn from Aboriginal principles that will improve education of all students.

Furthermore, as suggested by the Accord on Indigenous Education, "the time is right for a concerted and cooperative effort that creates transformational education by rejecting the "status quo," moving beyond "closing the gap discourse, and contribution to the well-being of Indigenous peoples and their communities” (Archibald, Lundy, Reynolds, \& Williams, 2010, p.2). However, it is important that the transformation includes all students and provides 
opportunities for all to think differently about the nature of education, their role as learners and teachers, and alternative ways of creating educational experiences for students. The Accord, although focused on improving educational opportunities and experiences for Indigenous students, notes that "major national studies and government commissions have called for this type of political and educational involvement” in decision-making and policy development, "and have recommended that Indigenous knowledge systems have a central position in educational policy, curriculum, and pedagogy" (Archibald et al., 2010, p.2). The Assembly of First Nations cited the Accord signed by the Canadian deans as a sign of the shift to address the undereducation of Canadians about the Indigenous peoples of Canada and committing to educational change (AFN, 2012, p.15)

In addition, the Accord identifies common traits of Indigenous education, including a holistic and lifelong framework, one that addresses spiritual, emotional, physical, and intellectual development in relation to oneself, one's family, community, and environment. The holistic model that defines Indigenous education implies multiple and diverse strategies, considering geographical, cultural, and linguistic diversity, which adds to the complexity and richness of education, and of society and should be embraced in Canadian society (AANDC, 1998). Indigenous education draws on an organic metaphor for learning that includes diversity as an asset, creating spaces to value and nurture multiple forms of knowing and ways of being in the world. As such, Indigenous education would embrace Eurocentrism as another form of knowing rather than the form of knowing.

\section{Decolonizing Teacher Education}

Our question is, then, "how are these Indigenous principles and related pedagogies informing and being interpreted in the practices of existing teacher education programs?” In the teacher education program at the University of Victoria, Dr. Lorna Williams' teaching has influenced how we think about teacher education, especially with several faculty taking Lorna's classes, and we have begun to respond to the ways in which Indigenous education can provide alternative perspectives and reshape our thinking about how preservice teachers can better prepare themselves for a teaching career. Using principles such as those listed below which were realized by Lorna Williams (2008) in her course, Teaching and Learning in an Indigenous world, we have attempted to conceive of a program that addresses the goals presented in the Accord and to address the challenges that come with shifting our collective and individual thinking. These include the need to provide:

- $\quad$ respectful and welcoming learning environments;

- $\quad$ respectful and inclusive curricula;

- culturally responsive pedagogies to improve the quality of knowledge, understanding, and pedagogic skills that all educators gain;

- mechanisms for valuing and promoting Indigeneity in education; and

- culturally responsive assessment (Archibald, Lundy, Reynolds, \& Williams, 2010, pp. 58). 
These goals have challenged us all to think about what and how future teachers need to consider their role as members of learning communities, the complexities of learning, the role of their students in learning communities, the role of past learning experiences and the influence of these experiences on their conceptions of learning and teaching. Though the Accord has been critiqued as fitting Aboriginal students into a Euro-Canadian schooling system and as not going far enough to embed Indigenous wisdom in the institution (Rasmussen, 2011), it does offer signposts for change. Wisdom keepers and institutional leaders at each site have the opportunity to define how Indigenous knowledge, wisdom, and practice will find a place in each institution, thus honouring the diversity of Indigenous peoples in Canada.

For centuries education has been structured in similar ways, but we are now at a critical juncture in educational history-education as we have known and experienced it is serving fewer and fewer of our students, including Canadian-born students of diverse descents, students who have immigrated to Canada, able/disabled populations, and students of all genders (Ralston Saul, 2008). We need alternative voices informing ways that teacher education programs can prepare teachers to meet the needs of all $21^{\text {st }}$ century learners. To that end, we have considered how teacher education programs might look if we shape them according to the principles introduced by Lorna Williams. We have considered small steps to (re)shape the program so that we can become more aware of the potentially oppressive nature of the program, recognizing and valuing experiences and cultures that differ from current norms and practices, seeking to reveal or uncover "othering" or exclusionary practices of societies and groups whom they want to subordinate (Levinas, 1969; Said, 1978), and challenging practices accepted as the norm.

\section{Lil'wat Principles}

In drawing explicitly on these Lil'wat principles highlighted and described in Figure 2 (Williams, 2008) below, we have asked the following questions: How does the adoption of these principles shift the ways that teacher education programs are offered? How does an explicit consideration of the next seven generations to come shape experiences in the program? How can we honour others' learning before our own, and understand the importance of recognizing and following our passions? How can these Lil'wat principles come to influence decisions made about teacher education and structures that contain the program?

\begin{tabular}{|l|l|}
\hline $\begin{array}{l}\text { Lil'wat } \\
\text { Principle }\end{array}$ & Description \\
\hline Kamúcwkalha & $\begin{array}{l}\text { acknowledging the felt energy indicating group attunement and the } \\
\text { emergence of a common group purpose }\end{array}$ \\
\hline$\underline{\text { Celhcelh }}$ & $\begin{array}{l}\text { each person being responsible for their own and others learning, always } \\
\text { seeking learning opportunities }\end{array}$ \\
\hline$\underline{\text { Kat'il'a }}$ & $\begin{array}{l}\text { seeking spaces of stillness and quietness amidst our busyness and quest for } \\
\text { knowledge }\end{array}$ \\
\hline$\underline{\text { A7xekcal }}$ & valuing our own expertise and considering how it helps the entire \\
\hline
\end{tabular}




\begin{tabular}{|l|l|}
\hline $\begin{array}{l}\text { Lil'wat } \\
\text { Principle }\end{array}$ & Description \\
\hline & community beyond ourselves \\
\hline Cwelelep & $\begin{array}{l}\text { recognizing the need to sometimes be in a place of dissonance and } \\
\text { uncertainty, so as to be open to new learning }\end{array}$ \\
\hline Emhaka7 & encouraging each of us to do the best we can at each task given to us \\
\hline
\end{tabular}

Figure 2. Lil'wat principles for learning and teaching.

Figure 2 offers six key Lil'wat principles with links to mp3 audio files that offer the appropriate pronunciation. The ideas introduced through these words offer an alternative way of thinking about teaching and learning, one that resists the colonial notions of competition, individualism, and scientific discourse that serve to suppress uncertainty and difference. Learning to say and use these words requires hearing the words as pronounced by Lil'wat speakers rather than mediated by English pronunciation; this is respectful to the Lil'wat. The effort to read and pronounce the Lil'wat words leads to news ways of embracing and addressing the challenges of a complex world.

The principle of Kamúcwkalha , acknowledging the felt energy indicating group attunement and the emergence of a common group purpose, describes a different relationship between individuals in a teacher education program. Creating conditions where a group is ready to work together, to listen to one another, and speak without fear suggests a different way of knowing and coming to learn. Recognizing social community as a vital component of learning, articulating the responsibility that each person has for helping the learning community to accomplish a task with good will, and understanding that relationships-with other students, the teachers and guides, the tasks, and the community-means that students are relating what they are experiencing to previous knowledge and to others.

Building on this principle, Celhcelh suggests that each person is responsible for his or her own learning, for finding and taking advantages of all opportunities to learn, and maintaining openness to learning. Each person must find their place in the community, and offer what knowledge and expertise they have to benefit the communal work being carried out. Embracing this principle requires a watchful listening, an openness to listening beyond our own personal thoughts and assumptions, being always aware and conscious of our surroundings as we focus on the task at hand.

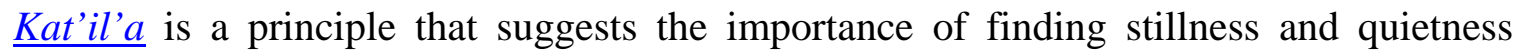
amidst our busyness and quest for knowledge. Within the increasing demands and speed in our lives, we need to seek out spaces that allow for changed pace, contemplating deeply our own experiences and the wisdom of others. 
It is within alternative spaces that the principle of $\underline{A 7 x e k c a l}$ can be lived; enabling us to locate the infinite capacity we have as learners, to develop our own gifts and passions in a holistic, respectful, and balanced manner. A7xekcal enables us to value our own expertise and consider how it helps the entire community, rather than just ourselves. Emhaka7 encourages each of us to do the best we can at each task given to us, and to be aware of how we can be helpful to others in our community. Emhaka7 reminds us to work respectfully and with good thoughts and good hands in all we do.

However, growth and learning requires that we continually challenge our established and comfortable ways of knowing and being; Cwelelep speaks of the need to be sometimes in a place of dissonance and uncertainty, in anticipation of new learning. Cwelelep can be described as spinning like a dust storm, dislodging learners from our places of mental, emotional, and physical comfort and begin to consider ideas in new ways. When new learning is emerging for

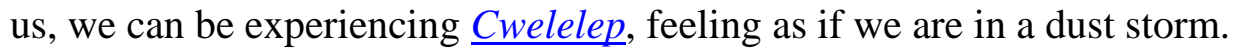

These principles resonate with many contemporary learning theories which highlight focused, situated (Barab \& Plucker, 2002), social (Wertsch, 1985) and complex (Davis \& Sumara, 2006) insights on learning. As such, notions of diversity within a collective system are seen as an asset, with interactions by participants in the collective promoted to allow systemwide learning and adaptation. In such a system, learning is based on participants' openness to ideas, and on interconnections made in personal contemplation, but also between people in the system who are drawn together by a common goal. Context then creates the conditions for persons to form a collective system, but at the same time, the context challenges the system to evolve, to exist with an element of uncertainty. Essentially, learning is seen as organic, emergent, and adaptive, continuously expanding the realm of possibility as the collective system seeks to thrive within ever changing and challenging contexts.

\section{Implementation of Lil'wat Principles}

The impact on our teacher education program has been both subtle and explicit. At first glance, the program seems similar to the one that was offered one or even two decades ago. However, shifts can be seen and felt in the way the program is offered, the ways in which students' contributions to the program have been recognized and valued, and the ways in which Indigenous ways of knowing have become integral to the overall program.

\section{Learning and Teaching in an Indigenous World: Transformational Course Experiences}

One of the most obvious influences has come from a course developed by Lorna Williams entitled Learning and Teaching in an Indigenous World. The course has had numerous iterations, beginning with a course that, in 2005, transformed our conceptions of learning and caused multiple dust storms. Lorna's proposal of a course in which Indigenous ways of knowing would be learned through carving a pole was received with trepidation and doubt. However, when completed, the course changed the ways of thinking for many people, including students, faculty, and community. Drawing on all of the Lil'wat principles identified above, Lorna's course modeled shared expertise (across multiple teachers, from within the student body, and from community members). It also opened up spaces for undergraduate and graduate students, 
and faculty to learn together in a common space in respectful and reciprocal ways. This course provided spaces for acknowledgement of cultural traditions, for valuing of multiple sources of wisdom, and for deep respect for generations of expertise. All members of the Pole Carving course were responsible for their own learning and for the learning of the group, as they assisted with the carving and the documenting of the learning that occurred during the course, and after the course was completed. Following iterations of the course (Earth Fibres; Storystick; Canoe

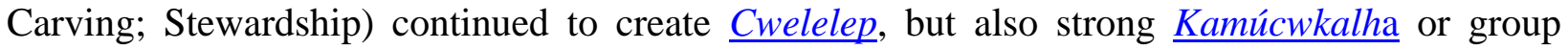
attunement and energy, Celhcelh as learning emerged in different ways for all members of the community, and Emhaka7 as respectful engagement was shown throughout.

As the Learning and Teaching in an Indigenous World courses developed, room was created in the program for another course, EI TELNIWT and Indigenous Education, to enable all students an opportunity to be introduced to alternative conceptions of learning through Indigenous principles, as well other optional courses such as Indigenous Epistemologies, The History of First Nations, Métis, and Inuit Education in Canada, and CENENITEL TW TOLNEW: Helping each other to learn. This course introduces an Indigenous world of learning and teaching through hands-on practical activities integrated with theoretical and academic goals. Experiences are offered in the principles of traditional Indigenous ways of teaching and learning such as mentorship and apprenticeship. Respectful practice, community engagement, and personal responsibility help learners develop insight into Indigenous pedagogy while working alongside community knowledge keepers, elders, and artists clearly demonstrating the infusion of Lil'wat principles.

\section{Alternative Practicum}

A second shift in the teacher education program was the introduction of an alternative practicum experience, recognizing that learning can occur in multiple locations and situations, and that many members of a community can be teachers. As preservice teachers seek out alternative sites in which to pursue their understanding of teaching (from the land, from elders, or from culturally diverse locations) they often find themselves in uncomfortable places (Cwelelep

) where many of their values and beliefs are challenged. They find themselves needing to exhibit watchful listening and Emhaka7 as they do the best they can in a new and challenging situation.

\section{Inquiry Courses}

A third site where Lil'wat principles have influenced the teacher education program has been in the inquiry-based learning courses. In the spirit of Celhcelh, all students are responsible for their learning as they select topics of significance to their development and seek out ways to develop further expertise in that area. Through opportunities to make choices about the focus of their learning, students are developing their own personal gifts and expertise in connected and relevant ways ( $\underline{\mathrm{A} 7 \mathrm{xekcal}}$ ), and becoming engaged in issues of personal and professional interest, need, and relevance. Instructors become more deeply aware of the competence, ability, and passion of each of their students about significant issues; they share their understandings, develop existing expertise, and challenge existing theories and practices related to teaching and learning. Through opportunities to select and explore issues of personal and professional 
relevance, students in the program have followed their passions to create curricular resources, and to research.

In some curriculum courses that have traditionally focused on examinable content, with students reading, remembering and recalling textbook-based material in exams and papers, instructors shifted their assignments to offer a more contract-based grading system. Essentially, if a series of mandatory assignments - engaging in discussion forums, annotating scholarly work, completing personal blogs on course experiences, and participating in field experiences-were done to a professional level, the student received a $\mathrm{B}+$ grade. All assignments had detailed criteria with examples available of previous assignments completed by students. To achieve a grade of "A," students were expected to complete a proposal template for an extension assignment that would contribute to their peers and their own learning. This shift created an expanding curriculum where students proposed assignments and negotiated the parameters for the assignment with the instructor based on the course materials. Students then worked on assignments where they invested in their own passions ( $\underline{\text { Celhcelh }}$

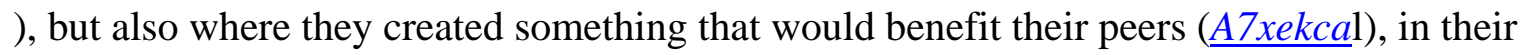
present class but also in subsequent classes. Extensions ideas drew from a wide set of experiences such as curriculum resources, YouTube videos on course content, assessment strategies piloted in local schools, field trips, inquiry projects, and workshops. Even when assignments were passed, several students indicated they intended on editing them based on instructor feedback before uploading them to their electronic portfolios. As one student commented after receiving feedback on her extension assignment: “Thank you for your feedback on my teaching behaviour analysis assignment...I will resubmit an updated version to be used as an example for future classes in the new year" (Student, personal communication, Mar 22, 2012).

\section{Electronic Portfolios (ePortfolios)}

Within our teacher education program an ePortfolio practice has been implemented that enables students to identify learning that relates to provincial standards that they have to address to be certified as a teacher. The ePortfolio enables students to develop and utilize technology skills learned in the program as well as create a reflective resource from which to draw when applying for teaching positions. As noted by Hopper and Sanford (2010) the ePortfolio has evolved as a mode of collecting evidence of deep and meaningful learning about the teaching profession. Students gather a range of artifacts, recollect the meaning behind each of these learning artifacts, and reflect on their significance to themselves and to the enhancement of their profession. Through a wide array of alternative modes showing evidence of learning, i.e., photographs, artwork, physical engagement, voice, or multimodal representations, students are enabled to demonstrate evidence of their learning, to take pride in the individuality of their work that becomes part of the community's understanding, and to share their learning with a broader community of learners. The diverse ways of representing their knowledge connects to others' learning artifacts and creates a more holistic understanding and demonstration (Hopper, Sanford, \& Bonsor-Kuki, 2012). Electronic portfolios also offer an alternative to traditional hierarchical assessment practices that often serve to fragment learning and alienate students from their own learning. Through the development of a rich array of learning artifacts, students take greater responsibility for their learning and recognize the relationships between different learning 
experiences in courses, outside experiences, and practicum experiences, making connections where none existed previously. Electronic portfolios break down barriers between students, drawing on Kamúcwkalha in order to engage with each other respectfully, sharing personal insights on theory and practice, but also on their reforming ideas on learning. These insights told diverse stories of becoming a teacher. The ePortfolios create a place for Celhcelh where students become more attuned to their own learning. As one student commented as she completed her teacher education program.

I had a conversation with a colleague about the ePortfolio, and I said, "Here, I think it's beneficial because now it's my choice, like what do I want to share and what do I want to think back and reflect on?" That's the power of eportfolio because rather than telling, it's like putting the power in the other person's hand, in the learner's hand. (Student, personal communication, April 5, 2010)

This shift from being told to taking responsibility for one's own learning resonates with the core

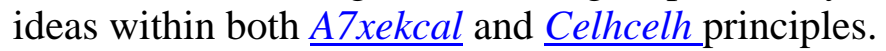

\section{Learning From Students}

The Lil'wat Principles of Teaching and Learning have enabled us to recognize gaps in the teacher education program and provide alternative spaces for student voices to emerge. The Underground Curriculum, a non-course created and offered by students in the program to offer opportunities for students to explore issues not addressed well enough in the program, was supported by teacher education personnel. Recognizing that teacher education programs are located in institutional frameworks that do not embrace change rapidly, both students and faculty sought to create alternative spaces to grow and nurture learning. These alternate learning spaces enabled $\underline{A 7 x e k c a l}$ as students explored issues of personal significance to them and their peers; they enabled Cwelelep, both through alternative spaces and challenging topics brought to light. Students who became involved in educational programs of Sea Change Marine Conservation Society experienced learning very differently as they engaged with children in hands-on learning with physical activities such as rowing, explorations on the beach, and learning from traditions of local First Nations communities. Alternately, students who chose to experience education in an Ugandan orphanage learned about cultural traditions and values, about teaching multi-age groups in spaces with very few educational resources, and ways to create innovative tools and strategies. Community among the students, and with a broad range of community organizations, developed through recognition of others who had the same interests and needs, providing new locations for new conversations that respectfully engaged in the work of becoming teachers.

\section{Embedded Teacher Education Practices}

In addition to these significant features of the teacher education program, other features of the teacher education program resonated with the Lil'wat principles. In many cases, students were organized in cohorts, giving them the opportunity to develop relationships with a group of colleagues over a year, rather than working with different people in each course. Students were offered a full day in the middle of the week for connecting, reconnecting, and reflecting, freeing them from formal commitments such as courses. This day allowed students to breathe deeply, to 
choose further learning opportunities, and to connect informally with their peers. Support was given to the Education Students' Association to create their own professional opportunities through invited guest speakers, participation in professional conferences, or creating informal support groups. A significant learning experience in the teacher education program is the professional seminars, developed to provide spaces for meaning making with elders and peers, for connecting collaboratively rather than competitively, to develop relationships, and to engage in Kamúcwkalha.

Many individual instructors created learning opportunities that resonated with the Lil'wat principles. This was especially the case for instructors who took Lorna's course, engaging in the Aboriginal principles as a member of the class. In many cases, the students were offered opportunities to work in groups, allowing them to share the work and their knowledge, and to provide each other with support and encouragement. For example, one instructor revised his course outline to focus on three core principles advocated by Lorna Williams (2008) within the learning and teaching in an Indigenous world course. As he stated,

To encourage students' collective identity, shared learning and co-operation, the rules of engagement in the course were given as: (1) put the learning of their peers before their own learning; (2) create work that will benefit seven generations to come; and (3) find their own passion in course content and use it to energize the community. (Instructor, personal communication, Sept. 2011)

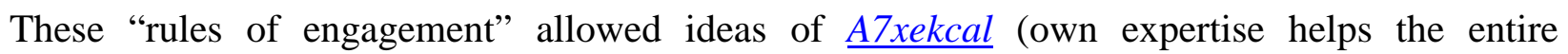
community beyond ourselves), Emhaka7 (encouraging each to do best we can in a task), and Celhcelh (responsible for own learning and seeking learning opportunities). He found that these simple rules resulted in the students developing a sense of collective identity and personal support for each other's learning. The course used a school-integrated approach to learning where some lessons were taught in a local school by the university instructor in collaboration with the schoolteacher and then gradually with the students (Hopper \& Sanford, 2008). This experience created the Kamúcwkalha idea where there was a common felt energy indicating group attunement and the emergence of a common group purpose around learning to be a teacher within a school. As one student commented within her personal reflection,

Dr. H. told us on the first day of class, "Focus on the learning of your peers." At first, I was kind of confused by this... learning, I thought, was something of a personal activity. But through peer assessment and teaching, I came to recognize just how important it is to focus on the learning of your peers - a huge part of personal growth comes from working with others and doing what you can to support their learning. This is especially true for teachers! (Student, weekly reflection, November $8^{\text {th }}, 2011$ )

Use of electronic forums, such as MOODLE, ${ }^{1}$ enables shared learning for not only the current class but also for future generations of students. Sharing enables students to take pride in their work, work more diligently on their projects, and collaborate more richly. Students were afforded opportunities to represent their learning in many diverse ways, including orally, visually, and through physical enactments, demonstrating the value of diversity of skills and talents. Artifacts such as button blankets, story sticks, and canoe paddles have become valued as 
evidence of learning. These types of learning artifacts have also influenced how other forms have become more accepted, such as video journals, student-developed workshops for their peers, student-generated websites, podcasts, and blogs, to name a few.

In addition, while many of these activities were not created with the Lil'wat principles in mind, they resonate with each of the principles, suggesting a powerful and significant connection that needs to be clearly articulated throughout the program. It is through the clear articulation of Indigenous principles that we can come to value more explicitly the learning conditions created in classrooms and in programs. The wisdom of our Indigenous colleagues can return us to appreciation of spaces that engage in collective and human learning endeavours, providing culturally responsive teaching with intention and purpose. The humanity of teacher education can be revitalized and reconceptualized through Indigenous principles such as those shared by Lorna Williams.

\section{Providing a Day of Stillness}

Wednesdays provided a departure from days filled with scheduled classes, seminars-no classes were scheduled, and students were invited to use the day to their best advantage. Drawing on the principle of Kat'il'a, we sought to create spaces of stillness and quietness amidst students' very hectic programs and lives. Students were able to get together informally to create networks and community, attend workshops of their choice, go on field trips outside of the scheduled timetable, or they were able to use the time for quiet reflection and contemplation. Taking time to breathe deeply, to connect to the world around them, and to regain a sense of balance are important aspects of learning and teaching, although often disregarded in conventional teacher education programs. Too often we view time not filled up with courses and other work with suspicion, and our reaction is to add more- $\underline{\text { Kat'il'a }}$

reminds us that we need balance in order to act with wisdom and professionalism. Wednesdays were one such space, in the middle of busy weeks, that enabled students to find that.

\section{Conclusion}

Through our work in shaping experiences for preservice teachers, we have come to realize the effort required to shift our conceptions and practices. Those of us working with Lorna, attempting to provide experiences that are more inclusive for our students, have had to challenge our own "tried and true" beliefs and assignments. We have also had to face challenges from our students who have not always appreciated the dissonance that has been introduced into their lives. We have been challenged by administrative structures and expectations requiring compliance with policies created from Euro-American-centric traditions and values.

As we have become aware of the untenable limitations of the structures and rules within the education system, we have created alternative approaches and descriptions of student learning activities. However, we have also been challenged to model the principles that we are espousing, living in tension, ourselves, returning repeatedly to examine what we are doing and what are our motivations. We have had to resist the desire to return to the familiar and comfortable-both for our students and for ourselves - and have persisted in living in Cwelelep that place of uncertainty in which new learning emerges. 
Through these tensions have come visions of new possibilities as we create conditions that support the wisdom of Lil'wat principles. Working with the students to acknowledge the limitations of previously exalted approaches to becoming a teacher, we have challenged ourselves to conceptualize alternatives. We accept the need for apprehension in our learning as we realize the importance of disruption if we are going to address the needs of our students and their right to learn in complex environments. The examples shared above have enabled a shift, but we still all struggle to live in the tensions of change as we reshape our practices and shift our pedagogical realities, embodying the transformative potential of struggle.

Indigenous principles offer new ways to think about teacher education-embracing alternative spaces, creating moments of stillness, creating dust storms to challenge complacency, generating common purpose, recognizing our responsible for each others' learning in respect and balance, and employing watchful listening as we can.

Schools and teacher education have long been tools for colonizing, suppressing, oppressing, or objectifying learners, particularly Aboriginal peoples but in some sense all learners. In this paper, we have shared how we have tried to create a new way to think about creating learning conditions that appreciate the strengths of all, develop confident and strong teachers/leaders who are aware of context, place, spaces for learning to emerge and grow. We believe we are moving in the right direction, but also know there are many more steps to take as we deepen our understanding of why changes need to be made and how Indigenous principles can assist us to walk new paths. 


\section{References}

AANDC (1998). Royal commission report on Aboriginal peoples. Ottawa. Retrieved from http://www.aadnc-aandc.gc.ca/eng/1307458586498

AFN (2012). Soul of sovereignty: The impact of culturally responsive education on the academic achievement of First Nations students. Retrieved from http://www.afn.ca/index.php/en/policy-areas/education/resources-updates/...

Archibald, J., Lundy, J., Reynolds, C., Williams, L. (2010). Accord on Indigenous education. Retrieved from www.csse.ca/ACDE

Asante, M. K. (1999). The painful demise of Eurocentrism. Trenton, NJ: Africa World.

Barab, S. A., \& Plucker, J. (2002). Smart people or smart contexts? Cognition, ability, and talent development in an age of situated approaches to knowing and learning. Educational Psychologist, 37(3), 165-182.

Battiste, M. (2002). Indigenous knowledge and pedagogy in First Nations education: A literature review with recommendations. Ottawa: National Working Group on Education.

Clarke, A., Erickson, G., Collins, S., \& Phelan, A. (2005). Complexity science and cohorts in teacher education. Studying Teacher Education, 1(2), 159-177.

Darling-Hammond, L. (2006). Constructing 21st-century teacher education. Journal of Teacher Education, 57(3), 300-314.

Davis, B., \& Sumara, D. (2006). Complexity and education: Inquires into learning, teaching and research. London: Lawrence Erlbaum.

Giroux, H. (1988). Schooling and the struggle for public life. Minneapolis: University of Minnesota Press.

Giroux, H. (2012). Education and the crisis of public values (pp. 1-129). New York: Peter Lang.

Hopper, T., \& Sanford, K. (2008). Using poetic representation to support the development of teachers’ knowledge. Studying Teacher Education, 4(1), 29-45.

Hopper, T., \& Sanford, K. (2010). Program-wide e-portfolios: Creating new spaces for an “inside-out” approach to teacher education. Resistance, support and renewal. Teacher Education Quarterly, Special Online Edition, 37(1), 1-28.

Hopper, T., Sanford, K., \& Bonsor-Kuki, S. (2012). Stitching together a teacher's body of knowledge: Frankie N Stein’s ePortfolio. eLearning and Digital Media 9(1), 42-55. 
Levinas, E. (1969). Totality and infinity: An Essay on exteriority. A. Lingis (Trans.). Pittsburgh: Duquesne University Press.

Little Bear, L., (2009). Naturalizing Indigenous knowledge: Synthesis paper. (ISBN: 978-1926612-32-4) University of Saskatchewan, Aboriginal Education Research Centre, Saskatoon, Sask. and First Nations and Adult Higher Education Consortium, Calgary, Alta. Retrieved from www.ccl-cca.ca

Kanu, Y., (2011). Integrating Aboriginal perspectives into the school curriculum: Purposes, possibilities, and challenges. Toronto: University of Toronto Press.

McLaren, P. (1988). On ideology and education: Critical pedagogy and the politics of education. Social Text, 19-20, Fall, 153-185.

Phelan, A. (2011). Towards a complicated conversation: teacher education and the curriculum turn. Pedagogy, Culture \& Society, 19(2), 207-220.

Ralston Saul, J. (2008). A Fair Country: Telling Truths About Canada. Toronto: Penguin.

Rasmussen, D. (2011). Some honest talk about non-Indigenous education. In E. Shaker (Ed.), Bright ideas: Students and educators challenge limits on education (pp. 19-33). Toronto: Our Schools/Our Selves.

Said, E. (1978). Orientalism. New York: Random House, Inc.

Smits, H., Wang, H.C., Towers, J., Crichton, S., Field, J., Tarr, P. (2005). Deepending Understanding of Inquiry Taching and Learning with ePortfolios in a Teacher Preparation Program. Canadian Journal of Learning and Technology, 31(3). http://www.cjlt.ca/index.php/cjlt/article/view/98/92

Trilling, B., \& Fadel, C. (2009). 21st century skills: Learning for life in our times. San Francisco: Jossey-Bass Publishers.

Wenger, E. (1998). Communities of practice. Cambridge: Cambridge University Press.

Wertsch, J. (1985). Vygotsky and the social formation of mind. London: Harvard Press.

Williams, L. (2008, 5 September). Storysticks: Learning and teaching in an Indigenous world. [University course].

Williams, L. and Michele Tanaka. (2007). Schalay’nung Sxwey’ga Emerging cross-cultural pedagogy in the academy. Educational Insights, 11(3). Available at: http://www.ccfi.educ.ubc.ca/publication/insights/v11n03/articles/william... 


\section{Endnote}

${ }^{1}$ MOODLE is a free, open-source learner management system for producing modular internetbased courses. Interactive processes support a social constructionist pedagogy - see http://docs.moodle.org/23/en/About_Moodle for an overview of the theory behind MOODLE. 